\title{
Atomic-Level Construction of Tensile-Strained PdFe Alloy Surface toward Highly Efficient Oxygen Reduction Electrocatalysis
}

Xu Li,$^{\dagger,}{ }^{\perp}$ Xingxing Li $,{ }^{\dagger}, \perp$ Chunxiao Liu $,{ }^{\dagger}, \stackrel{\perp}{ }$ Hongwen Huang,,,++ Pengfei Gao, ${ }^{\dagger}$ Fawad Ahmad,${ }^{\dagger}$

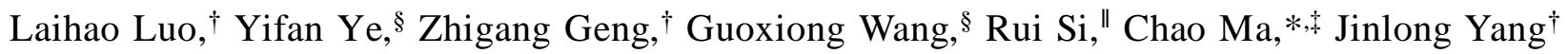
and Jie Zeng*,†

†Hefei National Laboratory for Physical Sciences at the Microscale, Key Laboratory of Strongly-Coupled Quantum Matter Physics of Chinese Academy of Sciences, National Synchrotron Radiation Laboratory, Key Laboratory of Surface and Interface Chemistry and Energy Catalysis of Anhui Higher Education Institutes, Department of Chemical Physics, University of Science and Technology of China, Hefei, Anhui 230026, P. R. China

College of Materials Science and Engineering, Hunan University, Changsha, Hunan 410082, P. R. China.

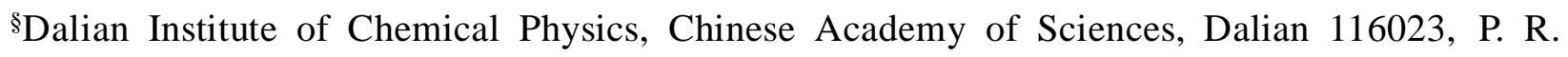
China.

"Shanghai Synchrotron Radiation Facility, Shanghai Institute of Applied Physics, Chinese Academy of Sciences, Shanghai 201204, P. R. China

*E-mail: huanghw@hnu.edu.cn (H.H.).

*E-mail: cma@hnu.edu.cn (C.M.).

*E-mail: zengj@ustc.edu.cn (J.Z.).

${ }^{\perp}$ These authors contributed equally to this work. 


\section{Experimental Details}

Chemicals. All chemicals were used as received. Palladium(II) acetylacetonate (Pd(acac)2, 99\%), oleylamine (OAm, 70\%, Aldrich), 1-octadecene (ODE, 90\%) were purchased from Sigma-Aldrich. Formaldehyde solution (37\%-40\%), hexane (A.R. grade), toluene (A.R. grade) were purchased from Sinopharm Chemical Reagent Co. Ltd. (Shanghai, China). Dodecacarbonyltriiron $\left(\mathrm{Fe}_{3}(\mathrm{CO})_{12}, 96 \%\right.$ dry wt, stab. with $5-10 \%$ methanol) was purchased from Aladdin Industrial Corporation.

Synthesis of Pd icosahedra. The Pd icosahedra were synthesized according to previous work. ${ }^{[\mathrm{S} 1]}$ In a typical synthesis, $12.2 \mathrm{mg}$ of $\mathrm{Pd}(\mathrm{acac})_{2}$ and $0.02 \mathrm{~mL}$ of OAm were dissolved in $5 \mathrm{~mL}$ of toluene to form a homogeneous solution. After vigorously stirred in room temperature for $10 \mathrm{~min}$, $25 \mathrm{uL}$ of formaldehyde was added. Then the mixture solution was stirred for another $10 \mathrm{~min}$. Afterwards, the solution was transferred into a 20 -mL Teflon-lined stainless steel autoclave and maintained at $100{ }^{\circ} \mathrm{C}$ for $8 \mathrm{~h}$. The product was washed with hexane for five times, and then redispersed in hexane for inductively coupled plasma-atomic emission spectroscopy (ICP-AES) test.

Synthesis of Pd@PdFe core-shell icosahedra. A solution of $4 \mathrm{~mL}$ of hexane containing $4 \mathrm{mg}$ of Pd icosahedra was mixed with $7 \mathrm{~mL}$ of ODE and $2 \mathrm{~mL}$ of OAm in a three-necked flask. The solution was heated to $110{ }^{\circ} \mathrm{C}$ under stirring and a continuous $\mathrm{N}_{2}$ flow to remove hexane. After that, $5 \mathrm{mg}$ of $\operatorname{Pd}(\mathrm{acac})_{2}$ was added to the system to be fully dissolved. Then $1 \mathrm{~mL}$ of ODE containing $1 \mathrm{mg}$ of dissolved $\mathrm{Fe}_{3}(\mathrm{CO})_{12}$ was injected into the solution. The solution was further heated to $180{ }^{\circ} \mathrm{C}$ at a rate of $1-2{ }^{\circ} \mathrm{C} / \mathrm{min}$ and kept at this temperature for 1 hour. The final product was washed with hexane for five times to remove the residual ions.

Synthesis of PdFe nanoparticles. The PdFe nanoparticles (NPs) were obtained by using the standard procedure except for the absence of Pd icosahedral seeds.

Molecular dynamics (MD) simulations. To keep consistent with experimentally prepared nanoparticle, a Pd icosahedral nanoparticle with edge length of $14.5 \mathrm{~nm}$ were built. Then we replace $9 \%$ of the outermost three layers of $\mathrm{Pd}$ atoms with $\mathrm{Fe}$ atoms. MD simulations were 
performed by LAMMPS with EAM interatomic potential of Pd-Fe alloy. ${ }^{[\mathrm{S} 2]}$ To obtain the equilibrium configuration, conjugated gradient (CG) minimization was first applied to the $\mathrm{Pd}$ icosahedral nanoparticle. After that we perform a molecular dynamics simulation at $50 \mathrm{~K}$ for 50 picoseconds, the last frame was taken out and optimized by the CG minimization procedure again. We firstly calculated the surface bond length of individual surface atom by averaging the lengths of all its bonds connecting to nearest-neighbor surface atoms. Then the strain of PdFe alloy surface was calculated based on the equilibrium bond length (2.751 $\AA$ ) in bulk of this Pd EAM potential. ${ }^{[\mathrm{S} 2]}$

Electrochemical measurements. Aside from the commercial $\mathrm{Pd} / \mathrm{C}$ and $\mathrm{Pt} / \mathrm{C}$, the other catalyst powders were prepared by loading the nanoparticles on carbon support (Vulcan XC-72) with a Pd loading content of $20 \mathrm{wt} \%$ (determined by ICP-AES). Typically, $5 \mathrm{mg}$ of nanoparticles (keeping $5.0 \mathrm{mg}$ of Pd in all samples determined by ICP-AES) were dispersed in $5 \mathrm{~mL}$ of hexane. $20.0 \mathrm{mg}$ of Vulcan XC-72 carbon and $20 \mathrm{~mL}$ of hexane were mixed and sonicated for two hours for full dispersion. Then the hexane solution containing nanoparticles were added into the Vulcan carbon solution in dropwise under vigorously stirring and further stirred overnight. The loaded catalysts were collected by centrifugation, then dried at $60^{\circ} \mathrm{C}$ in vacuum oven. After being dried, $5.0 \mathrm{mg}$ of the catalyst was redispersed in a mixed solution containing $1.500 \mathrm{~mL}$ of deionized water, $0.490 \mathrm{~mL}$ of isopropyl alcohol, and $0.010 \mathrm{~mL}$ of Nafion $(5 \%)$ under ultrasonication for $2 \mathrm{~h}$ to form homogeneous catalyst ink. Then, $6 \mathrm{uL}$ of the suspension was deposited on a glassy carbon rotating disk electrode (RDE) with a geometric area of $0.196 \mathrm{~cm}^{2}$.

Electrochemical measurements were carried out with a three-electrode system on an IM6 electrochemical workstation (Zahner, Germany). A Pt wire and $\mathrm{Ag} / \mathrm{AgCl}$ electrode were used as the counter and reference electrodes, respectively. All potentials mentioned in this work were measured against standard $\mathrm{Ag} / \mathrm{AgCl}$ electrode and converted to the reversible hydrogen electrode (RHE) scale. The cyclic voltammetry $(\mathrm{CV})$ measurements were processed in $\mathrm{KOH}(0.1 \mathrm{M})$ solutions under a flow of $\mathrm{N}_{2}$ at a sweep rate of $50 \mathrm{mV} \mathrm{s}^{-1}$. The ORR measurements were performed in $\mathrm{O}_{2}$-saturated $0.1 \mathrm{M} \mathrm{KOH}$ at a rotation rate of $1600 \mathrm{rpm}$ and a sweep rate of $10 \mathrm{mV}$ $\mathrm{s}^{-1}$. Durability test was performed at room temperature by applying cyclic sweeps between 0.6 and $1.1 \mathrm{~V}_{\mathrm{RHE}}$ in $0.1 \mathrm{M} \mathrm{KOH}$ at a sweep rate of $100 \mathrm{mV} \mathrm{s}^{-1}$. The mass and specific activities were obtained by normalizing the kinetic current densities to the loading Pd mass and real active 
surface area.

Fuel cell test. The Pd@PdFe core-shell icosahedra/C and commercial Pt/C catalysts used for alkaline direct methanol fuel cell (ADMFC) test were $40 \%$ mass loading. Catalyst inks were made by mixing the catalyst powder, ethanol and 5\% Nafion ionomer solution. The catalyst layer was prepared onto the gas diffusion layer of Toray TGP-H-060 carbon paper. The catalyst loadings of the ADMFC with Pd@PdFe core-shell icosahedra/C or commercial Pt/C as cathodes and PtRu/C black as anode were $3.0 \mathrm{mg} \mathrm{cm}^{-2}$. The fuel cell consisted of two compartments with $2 \mathrm{~mm}$ parallel channels was employed as flow fields for methanol and oxygen flow (Figure S24). The solution containing $2 \mathrm{M}$ methanol and $2 \mathrm{M} \mathrm{KOH}$ was used as fuel. The fuel solution was pumped to anode at a flow rate of $5 \mathrm{~mL} \mathrm{~min}^{-1}$ and dry oxygen $\mathrm{w}$ as supplied to the cathode with a flow rate of $100 \mathrm{~mL} \mathrm{~min}^{-1}$. Heating plates and temperature controller were used to maintain the operating temperature at $60{ }^{\circ} \mathrm{C} .{ }^{[\mathrm{S} 3]}$

DFT calculations. To simulate the tensile-strain PdFe alloy surface, a six-layer Pd (111) slab was constructed first, and then the top three layers were doped with three Fe atoms, with bottom two layers fixed to the bulk Pd structure. Considering the experimental results and the strong $\mathrm{Fe}-\mathrm{O}$ bonding, we saturated the outmost Fe atom with three $\mathrm{OH}$ groups (Figure S23). In order to reveal the relationship between ORR activity and $\mathrm{Fe}$ concentration, $\mathrm{a} \sqrt{7} \times \sqrt{7}$, $3 \times 3,2 \sqrt{3} \times 2 \sqrt{3}, \sqrt{19} \times \sqrt{19}$ supercell of Fe doped $\mathrm{Pd}$ (111) slab was built, respectively. Correspondingly, the atomic ratio of Fe in the surface alloy shell is $14.3 \%, 11.1 \%, 8.3 \%, 5.3 \%$, respectively. For each supercell model, biaxial tensile strain ranging from $0 \%$ to $6 \%$ was applied with an increment of $2 \%$ to study the response of ORR activity with respect to strain. To describe the ORR activity, oxygen adsorption on favorable fcc hollow site was calculated. The adsorption energy is defined as $E_{o}=2 E_{\text {slab }}+E_{o_{2}}-2 E_{\text {slab }-o}$, where $E_{\text {slab }}, E_{\text {slab }-o}$ is the total energy of slab without and with $\mathrm{O}$ adsorbed, respectively. In this definition, more positive values of $E_{\mathrm{O}}$ indicate stronger adsorption. As a comparison, oxygen adsorption on pure Pd (111) and Pt (111) surfaces was also computed. Due to the doping of Fe atoms, the fcc hollow sites on Pd (111) surface are no longer equivalent, and would show different properties for oxygen adsorption. Therefore, to give an overall evaluation of ORR activity, we simulated the oxygen adsorption on all the 
possible fcc hollow site and obtained an averaged adsorption energy.

Spin polarized calculations were carried out within the Perdew-Burke-Ernzerhof generalized gradient approximation (GGA) with D3 type van der Waals interaction (vdW) correction implemented in Vienna ab initio simulation package (VASP). ${ }^{[S 4-6]}$ The projector augmented wave (PAW) potential and the plane-wave cut-off energy of $400 \mathrm{eV}$ were used. Monkhorst-Pack k-point meshes with k-point spacing of $0.15 \AA^{-1}$ were employed. ${ }^{[57]}$ Adjacent slabs were separated by a vacuum space of $10 \AA$ along the z-direction to eliminate their interactions. Dipole corrections were applied. During structural optimizations, the atoms of bottom two layers were fixed while other atoms were fully relaxed until the force was less than $0.01 \mathrm{eV} / \AA$. The criterion for the total energy was set as $1 \times 10^{-6} \mathrm{eV}$. To confirm the validity of our method, the lattice constants of bulk Pd and Pt were optimized to be $3.886 \AA$ and $3.935 \AA$, respectively, consistent well with the experimental values (the mismatch being $\sim 0.3 \%$ ).

Characterization. Transmission electron microscopy (TEM) images was taken using Hitachi 7700 microscope at an acceleration voltage of $100 \mathrm{kV}$. High-angle annular dark-field scanning transmission electron microscopy (HAADF-STEM) images, energy-dispersive X-ray spectroscopy (EDX) technique and electron energy-loss spectroscopy (EELS) analyses were collected on a JEOL ARM-200F microscope equipped with a probe-forming aberration corrector operated at $200 \mathrm{kV}$. X-ray photoelectron spectroscopy (XPS) analysis was carried out on an ESCALAB $250 \mathrm{X}$-ray photoelectron spectrometer with $\mathrm{Al} \mathrm{K} \alpha$ as the excitation source. The metal concentrations of Pd and Fe were determined by inductively coupled plasma-atomic emission spectroscopy (ICP-AES) (Atomscan Advantage, Thermo Jarrell Ash, USA). The X-ray Absorption Fine Structure (XAFS) measurements were carried out at Fe $K$-edge $\left(E_{0}=7712 \mathrm{eV}\right.$ ) on the BL14W1 beamline of Shanghai Synchrotron Radiation Facility. The XAFS data of Pd@PdFe core-shell icosahedra were recorded under fluorescence mode with a Lytle ion chamber.

Data availability. The data that support the findings of this study are available from the corresponding author on request. 

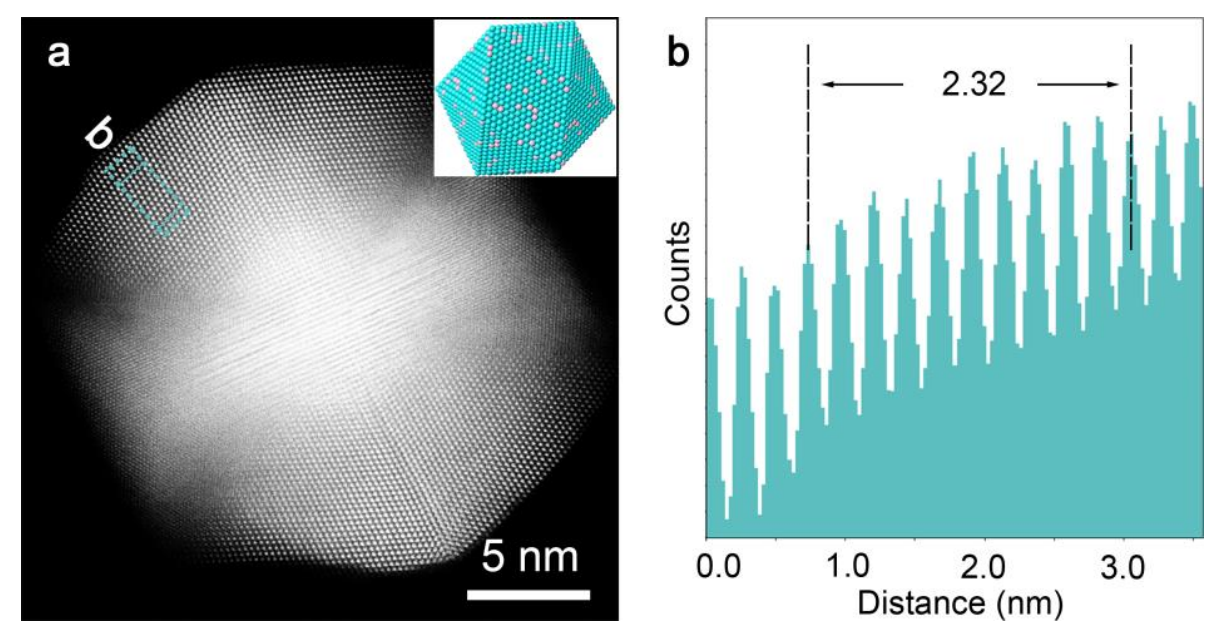

Figure S1. (a) Atomic-resolution HAADF-STEM image of Pd@PdFe core-shell icosahedral particle. (b) Intensity profile recorded from the area indicated by the rectangular box in panel (a). 


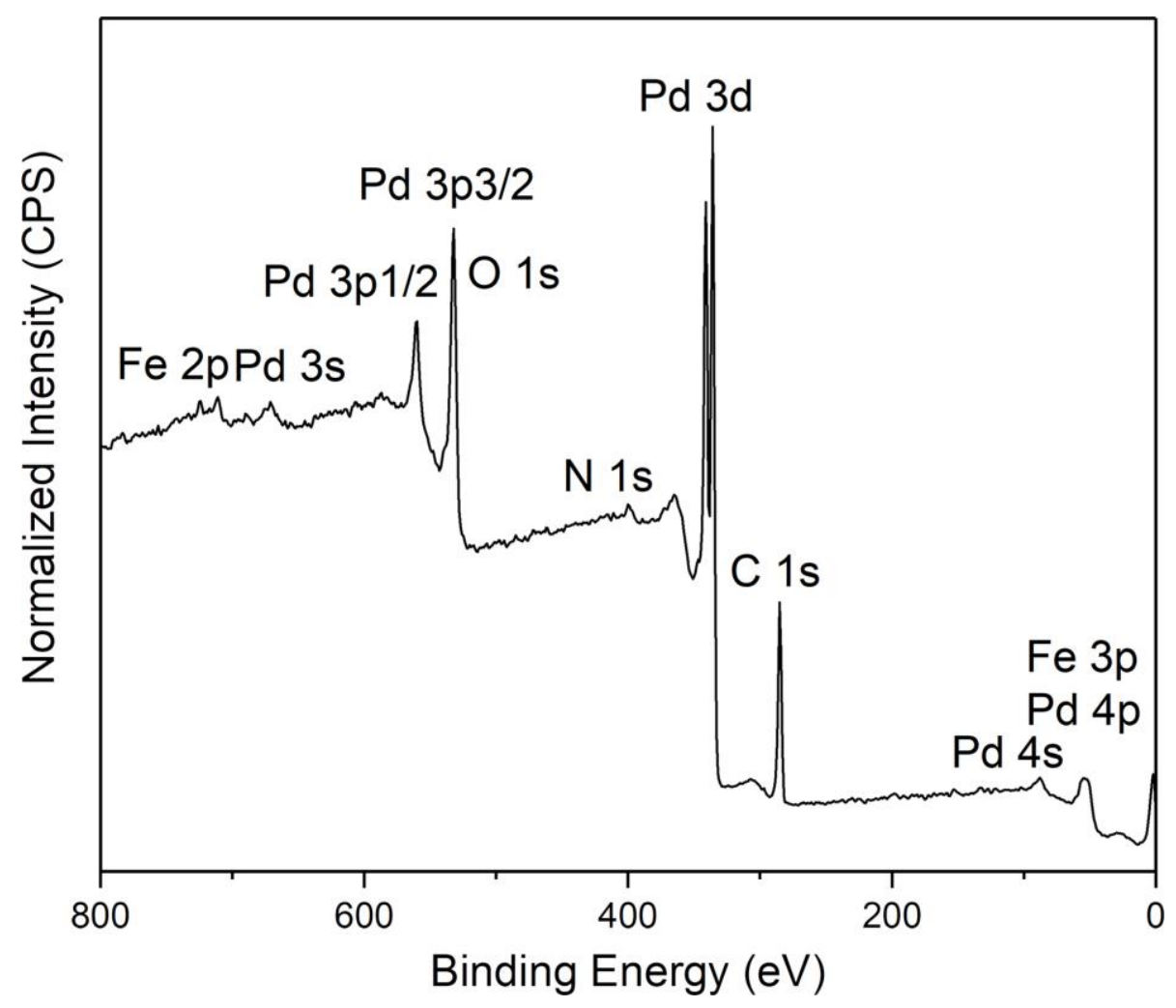

Figure S2. The XPS survey spectrum of the Pd@PdFe core-shell icosahedra catalyst. 


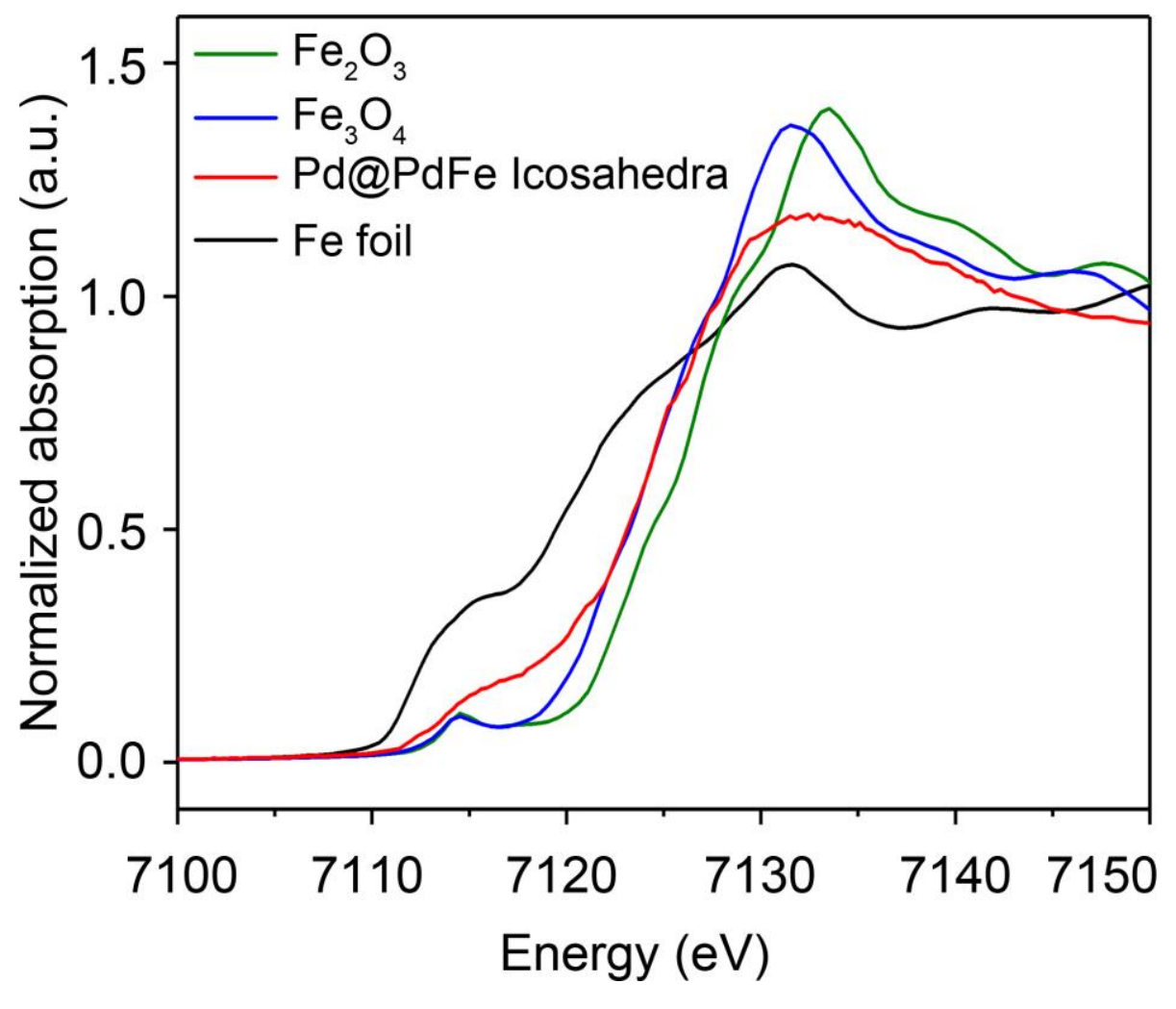

Figure S3. Fe K-edge XANES profiles of Pd@ PdFe core-shell icosahedra. Fe foil, $\mathrm{Fe}_{2} \mathrm{O}_{3}$ and $\mathrm{Fe}_{3} \mathrm{O}_{4}$ were used as standard samples. 


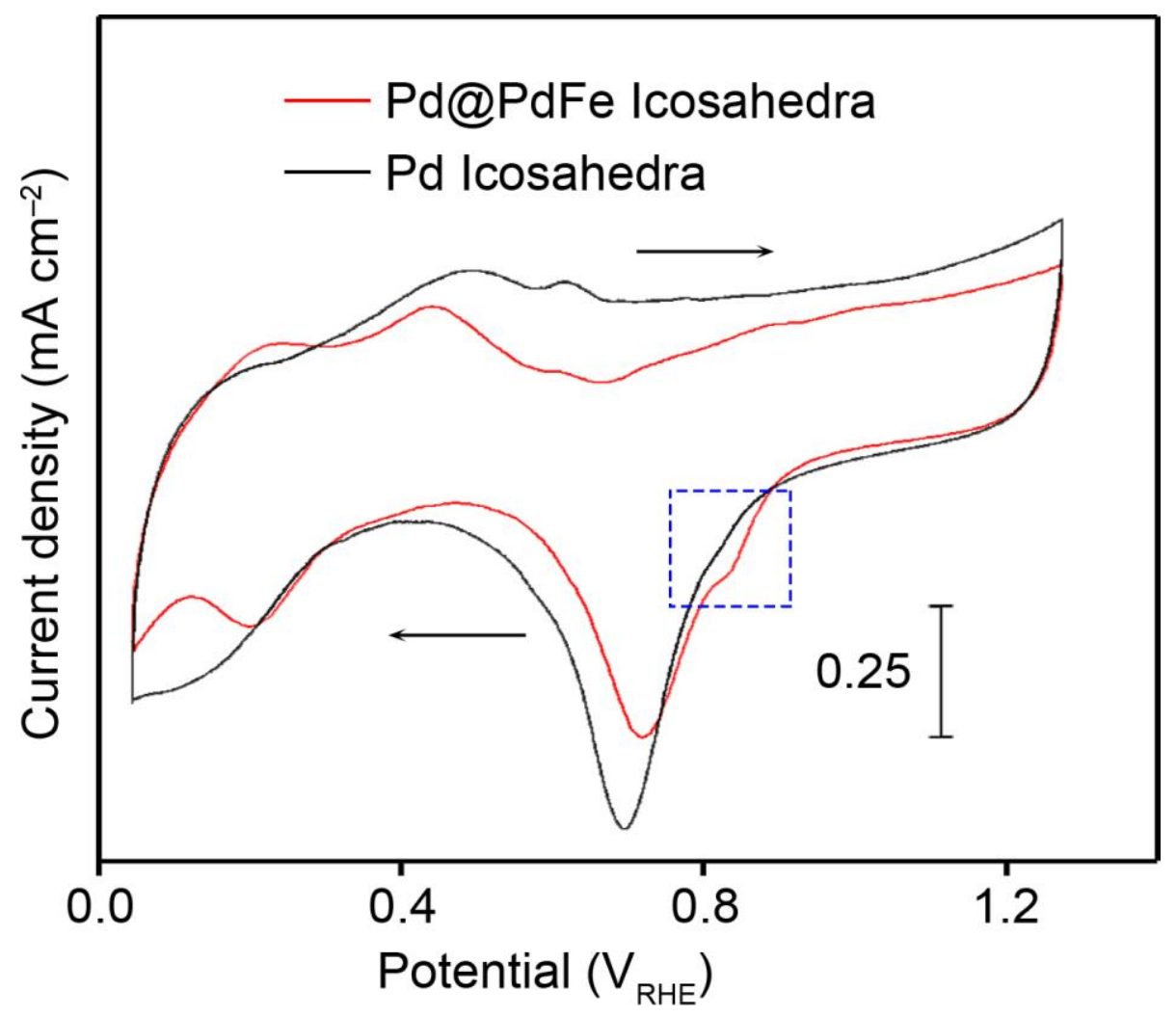

Figure S4. Cyclic voltammograms of Pd icosahedra/C and Pd@PdFe core-shell icosahedra/C recorded at room temperature in a $\mathrm{N}_{2}$-purged $0.1 \mathrm{M} \mathrm{KOH}$ solution with a sweep rate of $50 \mathrm{mV} \mathrm{s}^{-}$ 1. 

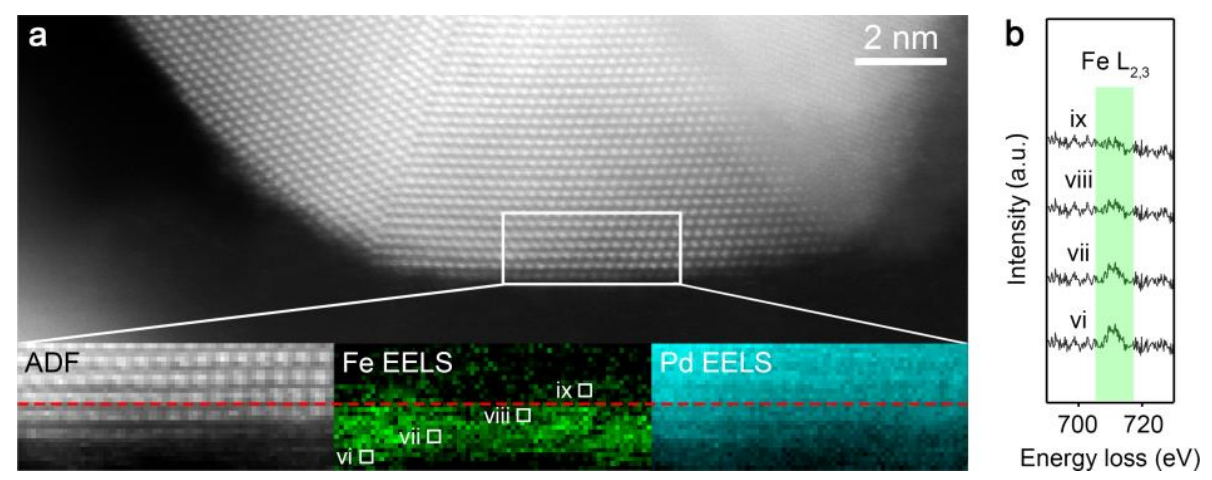

Figure S5. (a) HAADF-STEM image of Pd@PdFe core-shell icosahedra, which was captured from another particle, with insets showing atomically resolved EELS mapping images of the marked regions for Fe (green) and Pd (cyan), as well as a simultaneously acquired ADF image. (b) Corresponding electro-energy loss spectra of $\mathrm{Fe} \mathrm{L}_{2,3}$ acquired in different layers at marked points (vi-xi) in (a). 


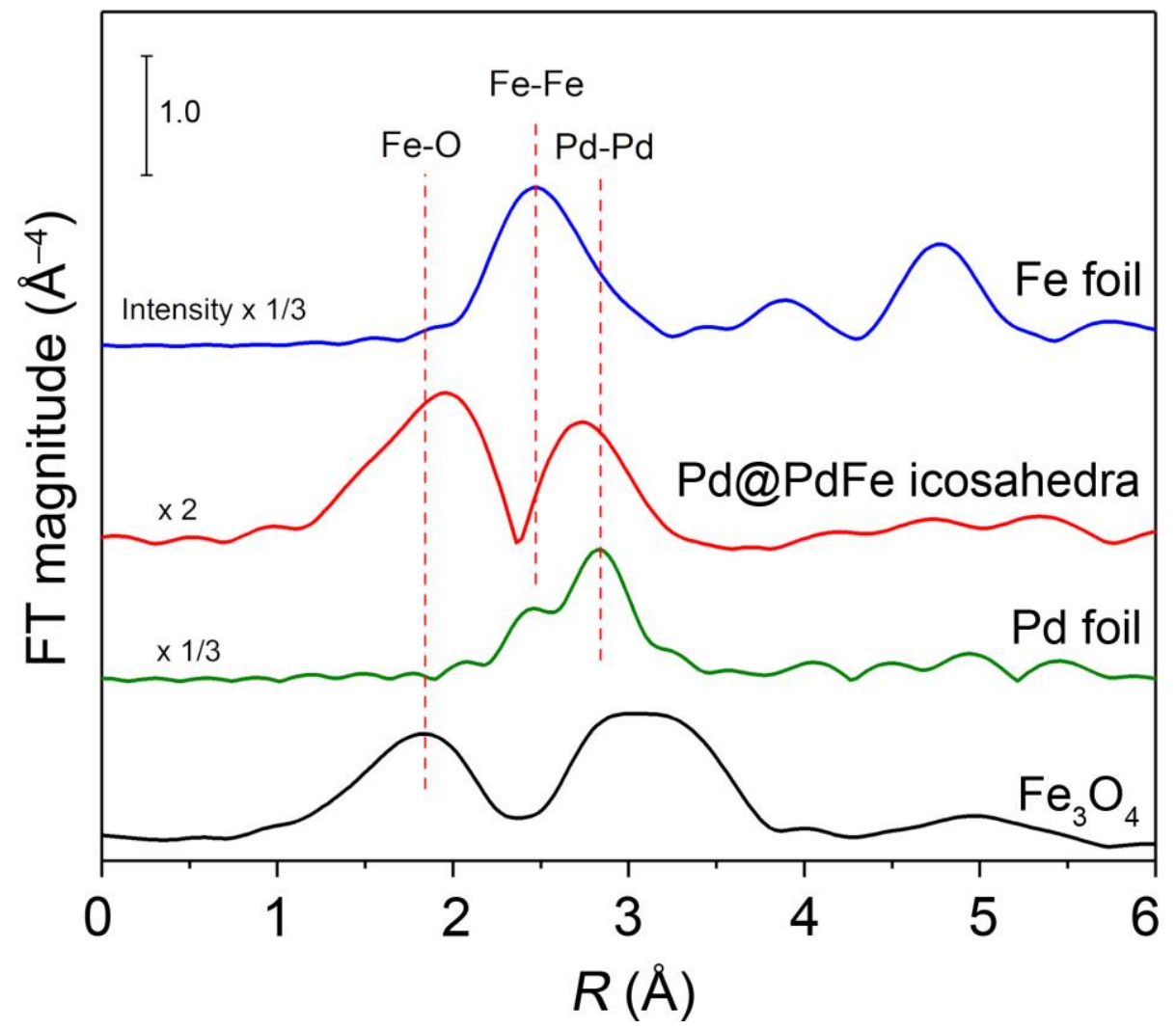

Figure S6. Fe K-edge EXAFS spectra in $R$ space of Pd@PdFe core-shell icosahedra, $\mathrm{Fe}_{2} \mathrm{O}_{3}, \mathrm{Fe}$ foil. Pd K-edge EXAFS spectrum of Pd foil. The peak at $2.7 \AA$ of Pd@PdFe core-shell icosahedra was assigned to Fe-Pd bond. 


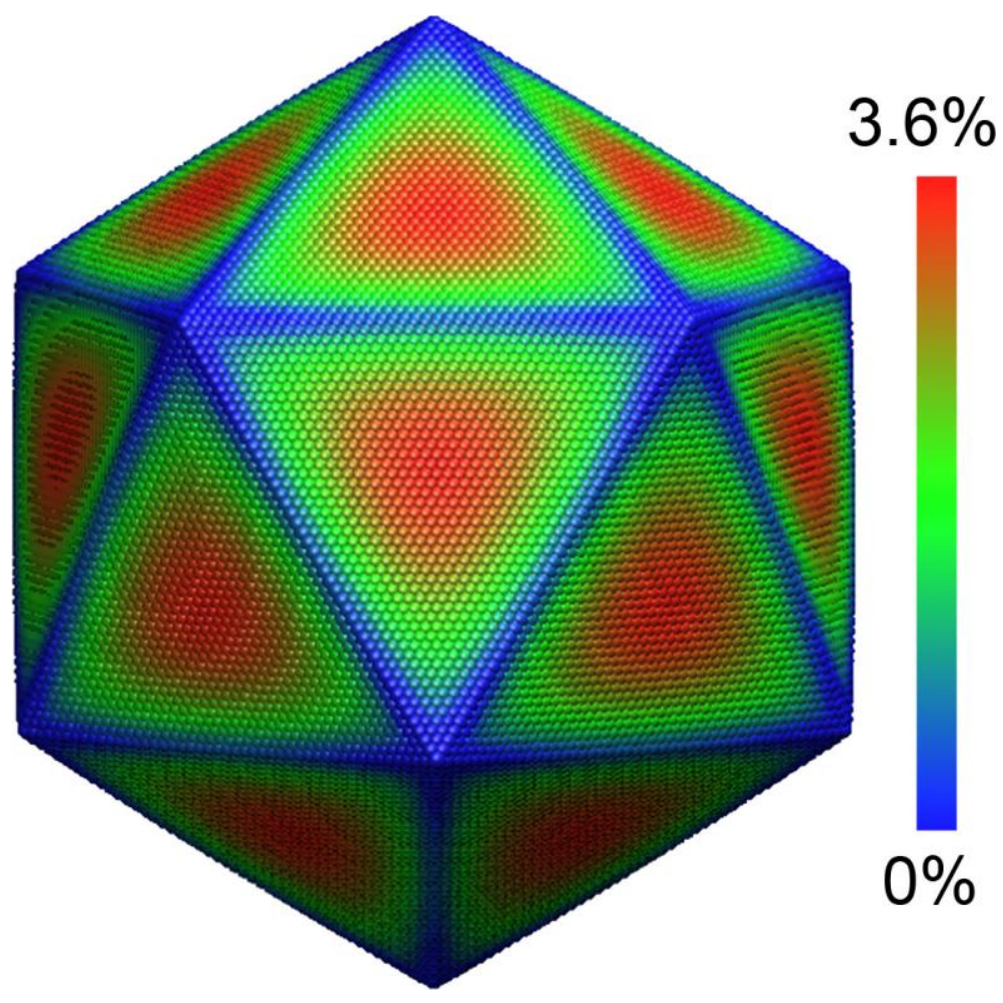

Figure S7. Surface strain field of the Pd icosahedra obtained using MD simulations. Color indicates strain labeled in the color map. 

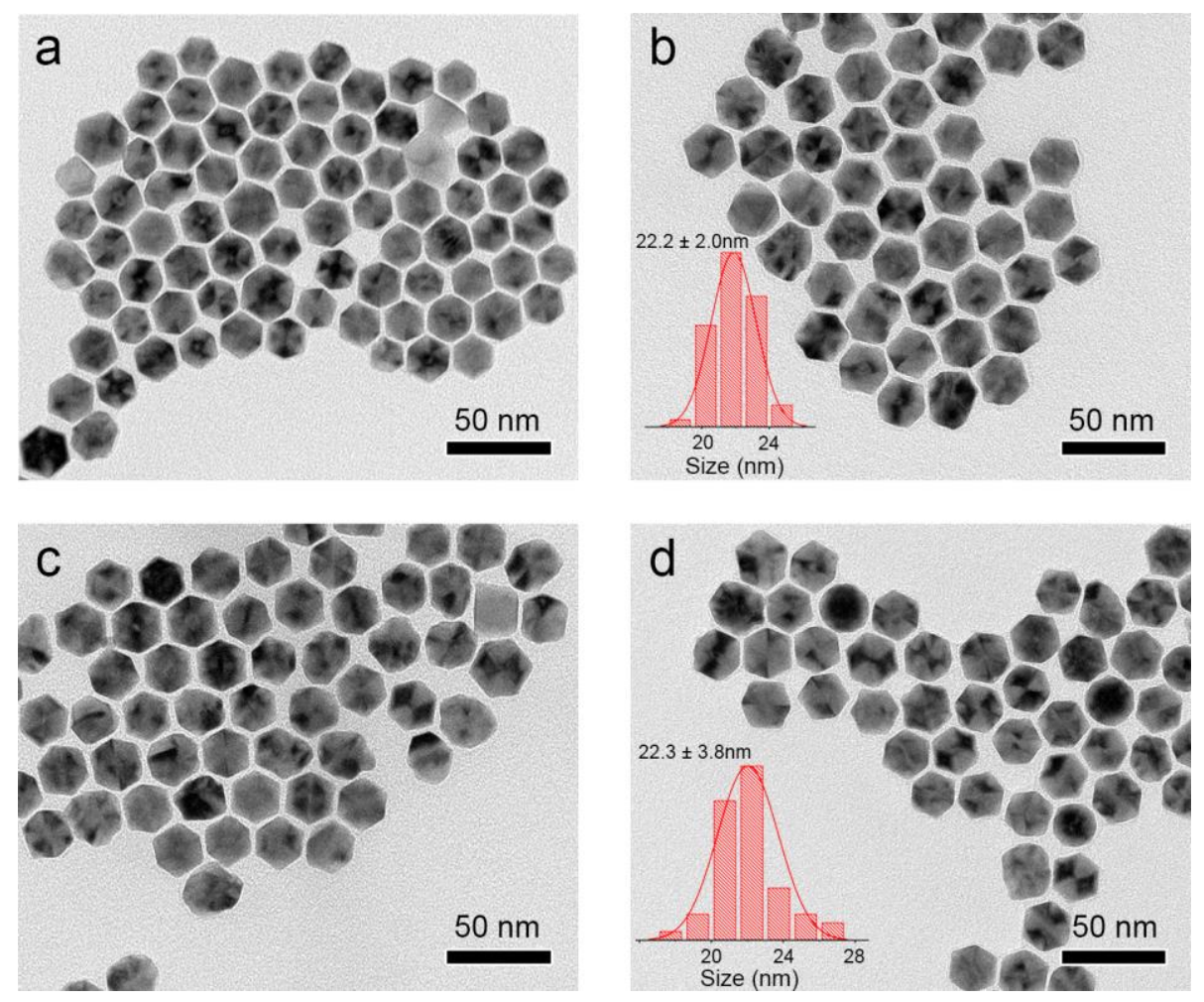

Figure S8. TEM images of (a) $\mathrm{Pd}$, (b) $\mathrm{Pd} @ \mathrm{Pd}_{0.94} \mathrm{Fe}_{0.06}, \quad$ (c) $\mathrm{Pd} @ \mathrm{Pd}_{0.91} \mathrm{Fe}_{0.09}$, and (d) $\mathrm{Pd} @ \mathrm{Pd}_{0.87} \mathrm{Fe}_{0.13}$ core-shell icosahedra. 


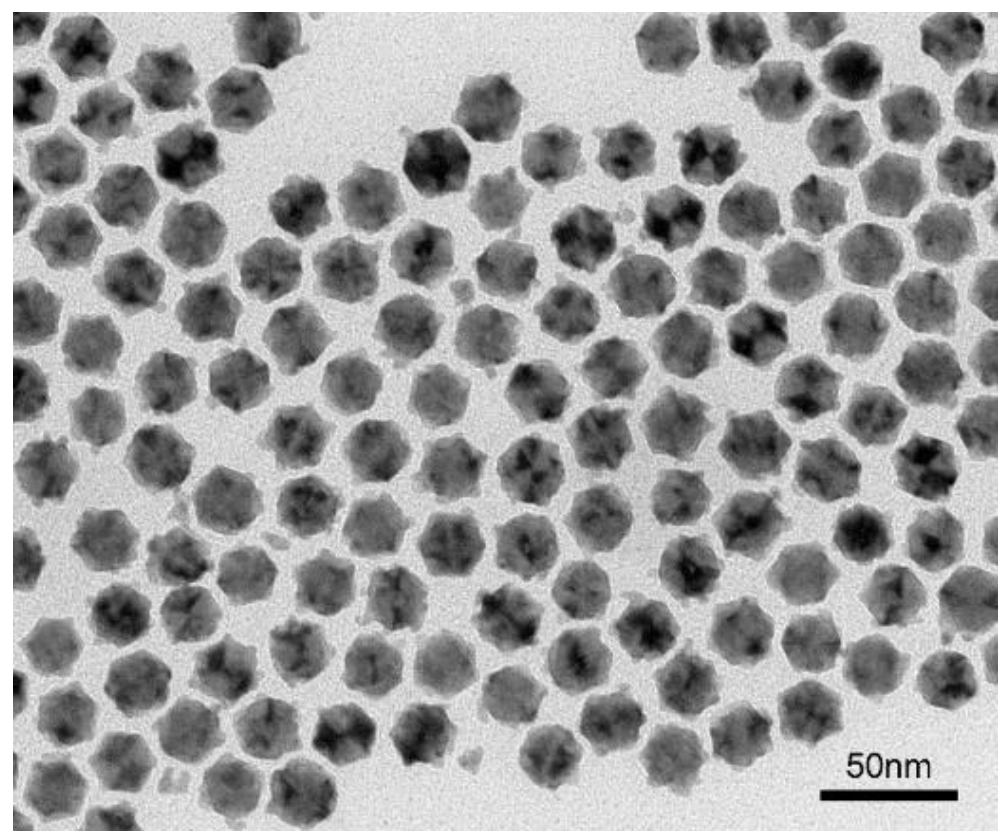

Figure S9. TEM image of the Pd@PdFe icosahedra synthesized by increasing $\mathrm{Fe}_{3}(\mathrm{CO})_{12}$ to 3 mg. 


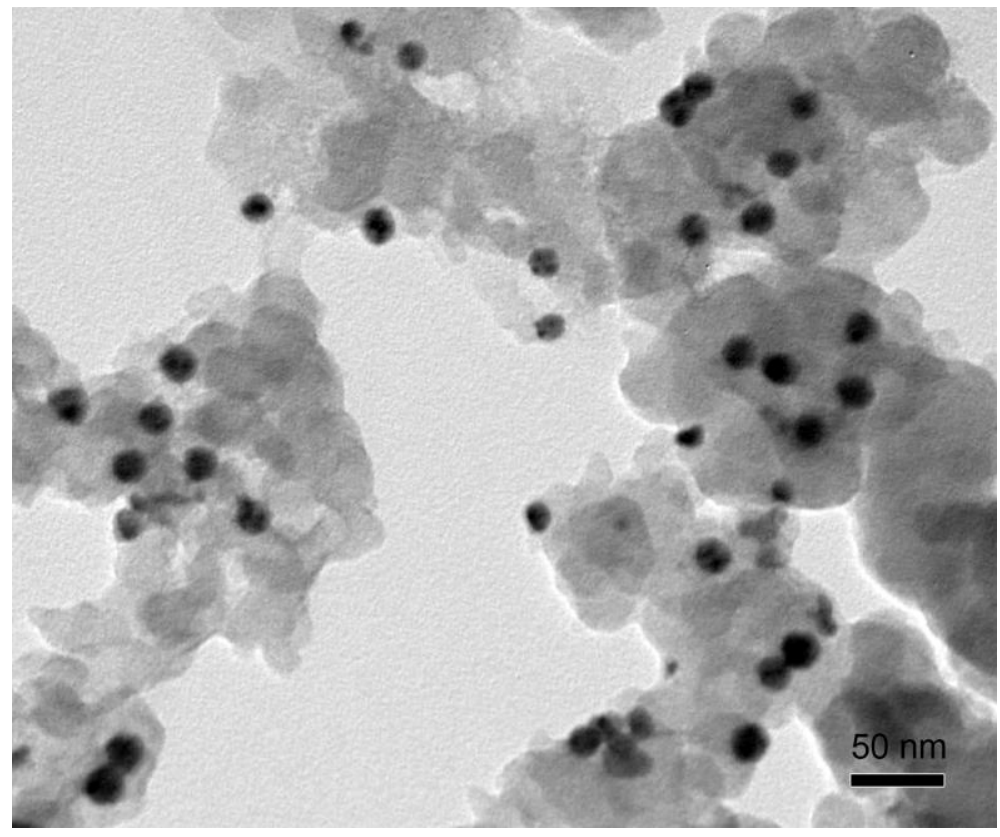

Figure S10. TEM image of Pd@ PdFe core-shell icosahedra catalyst loaded on carbon. 

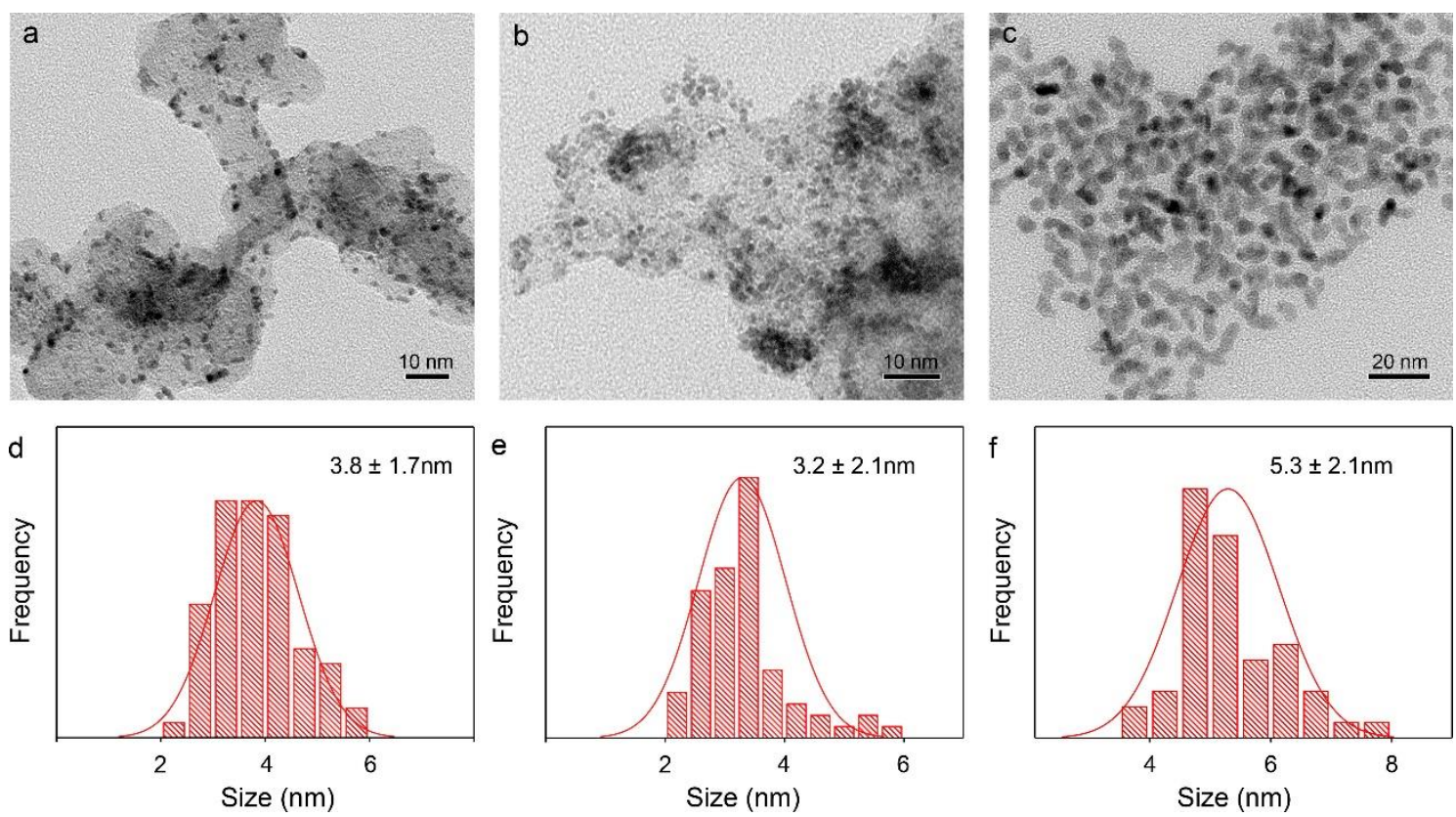

Figure S11. TEM images of (a) commercial Pt/C, (b) commercial $\mathrm{Pd} / \mathrm{C}$ and (c) $\mathrm{PdFe}$ alloy nanoparticles. Corresponding size distributions of (d) commercial Pt/C, (e) commercial Pd/C and (f) PdFe alloy nanoparticles. 

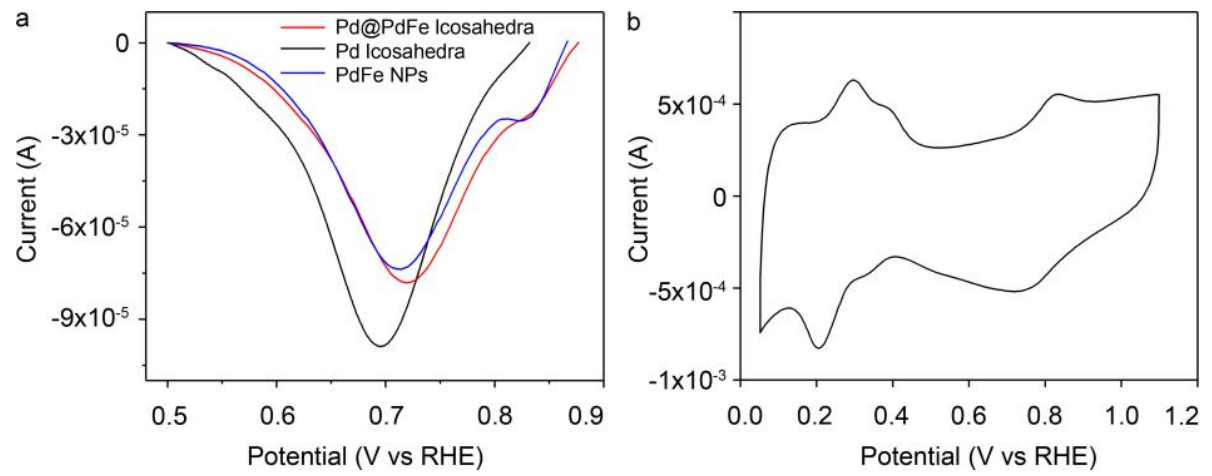

Figure S12. (a) PdO peaks of Pd@PdFe core-shell icosahedra/C, Pd icosahedra/C, PdFe alloy nanoparticles/C in Cyclic voltammograms, respectively. (b) Cyclic voltammograms of commercial Pt/C. All of the $\mathrm{CVs}$ were recorded at room temperature in a $\mathrm{N}_{2}$-purged $0.1 \mathrm{M} \mathrm{KOH}$ solution with a sweep rate of $50 \mathrm{mV} \mathrm{s}^{-1}$.

Table S1. The ECSAs of different Pd-based catalysts.

\begin{tabular}{|l|l|}
\hline Catalysts & ECSAs $\left(\mathrm{m}^{2} \mathrm{~g}^{-1}\right)$ \\
\hline Pd icosahedra & 20.9 \\
\hline $\mathrm{Pd} @ \mathrm{Pd}{ }_{94} \mathrm{Fe} 6$ core-shell icosahedra & 19.8 \\
\hline $\mathrm{Pd} @ \mathrm{Pd} 91 \mathrm{Fe} 9$ core-shell icosahedra & 19.3 \\
\hline $\mathrm{Pd} @ \mathrm{Pd}{ }_{87} \mathrm{Fe} 13$ core-shell icosahedra & 18.3 \\
\hline $\mathrm{PdFe} \mathrm{NPs}$ & 17.6 \\
\hline
\end{tabular}




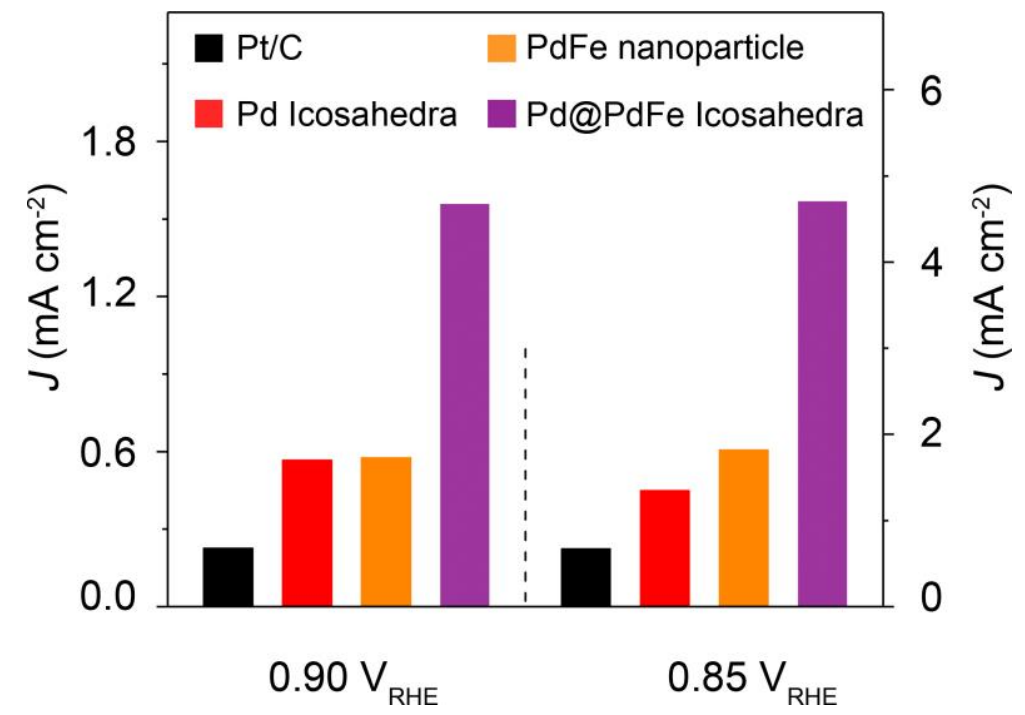

Figure S13. Specific activities at $0.90 \mathrm{~V}_{\mathrm{RHE}}$ and $0.85 \mathrm{~V}_{\mathrm{RHE}}$ for different catalysts. 

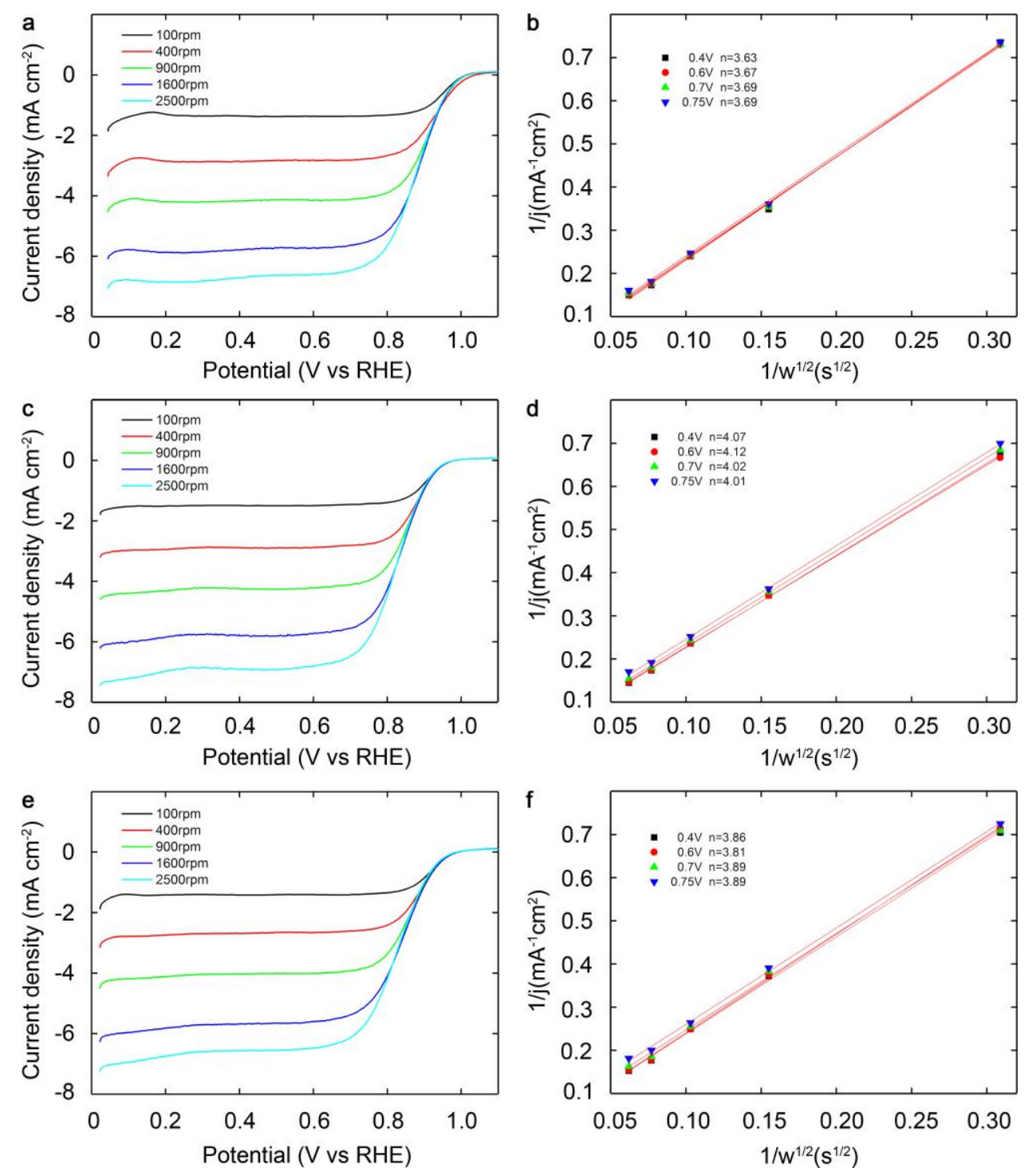

Figure S14. Polarization curves at variable rotation rate and Koutecky-Levich plots showing number of transferred electrons (n) per $\mathrm{O}_{2}$ for $\mathrm{Pd} @ \mathrm{PdFe}$ core-shell icosahedra/C (a and b), $\mathrm{Pd}$ icosahedra/C (c and d) and PdFe alloy nanoparticles/C (e and f). 


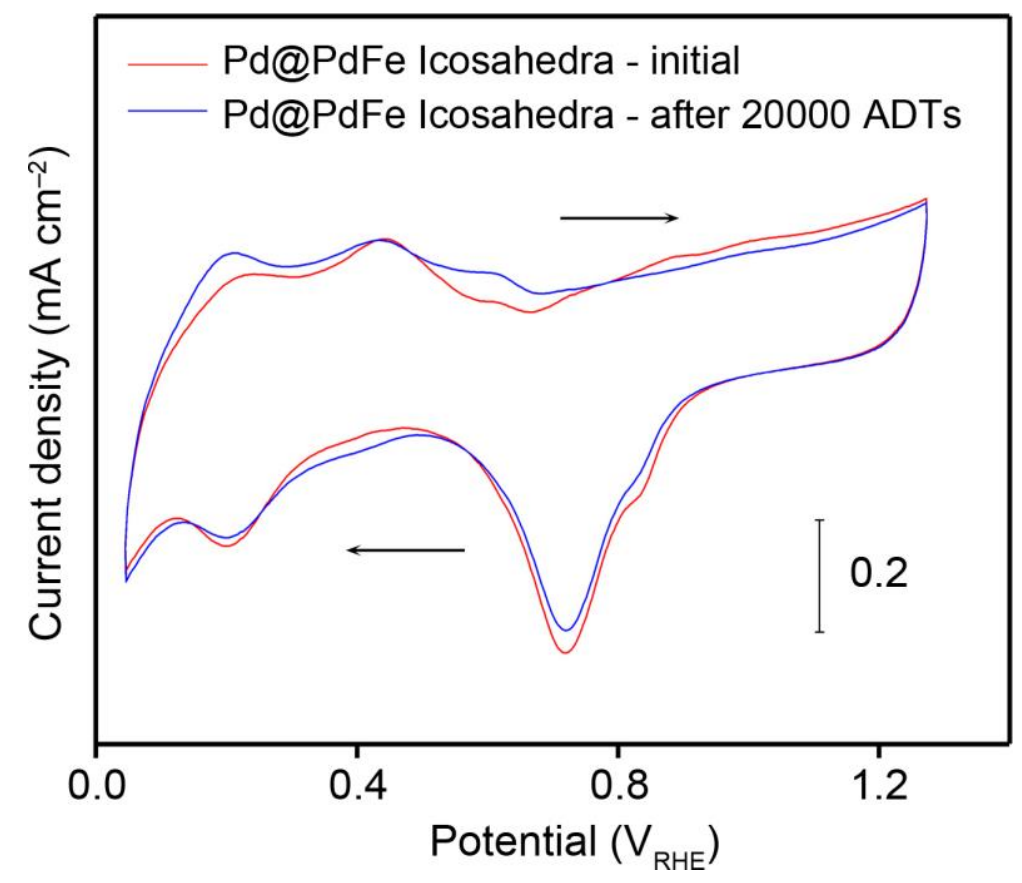

Figure S15. Cyclic voltammograms of Pd@PdFe core-shell icosahedra/C recorded before and after 20000-cycle ADTs. 

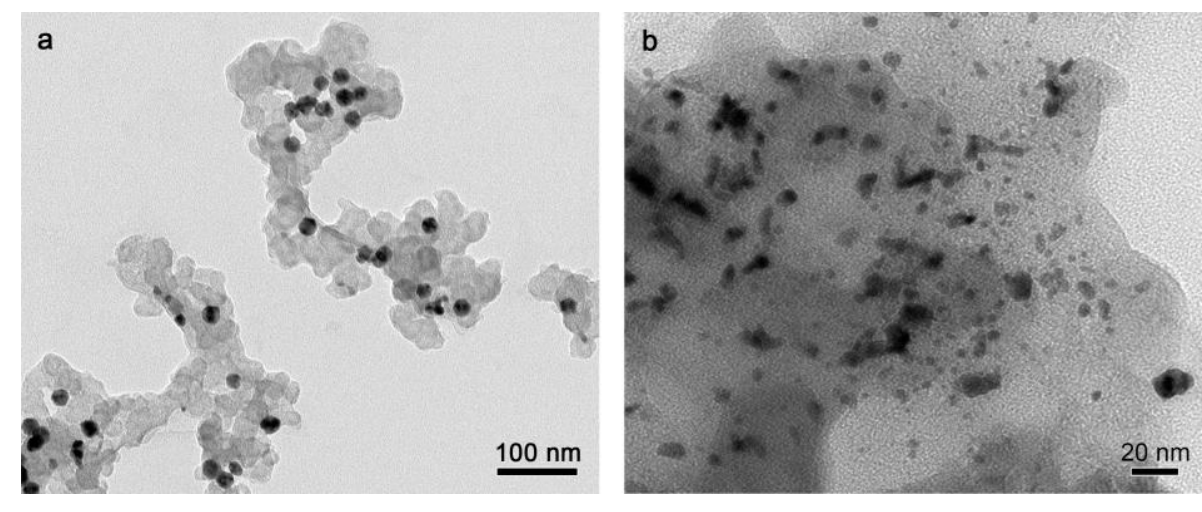

Figure S16. TEM images of (a) Pd@ PdFe core-shell icosahedra/C and (b) commercial Pt/C after 20000-cycle ADTs. 


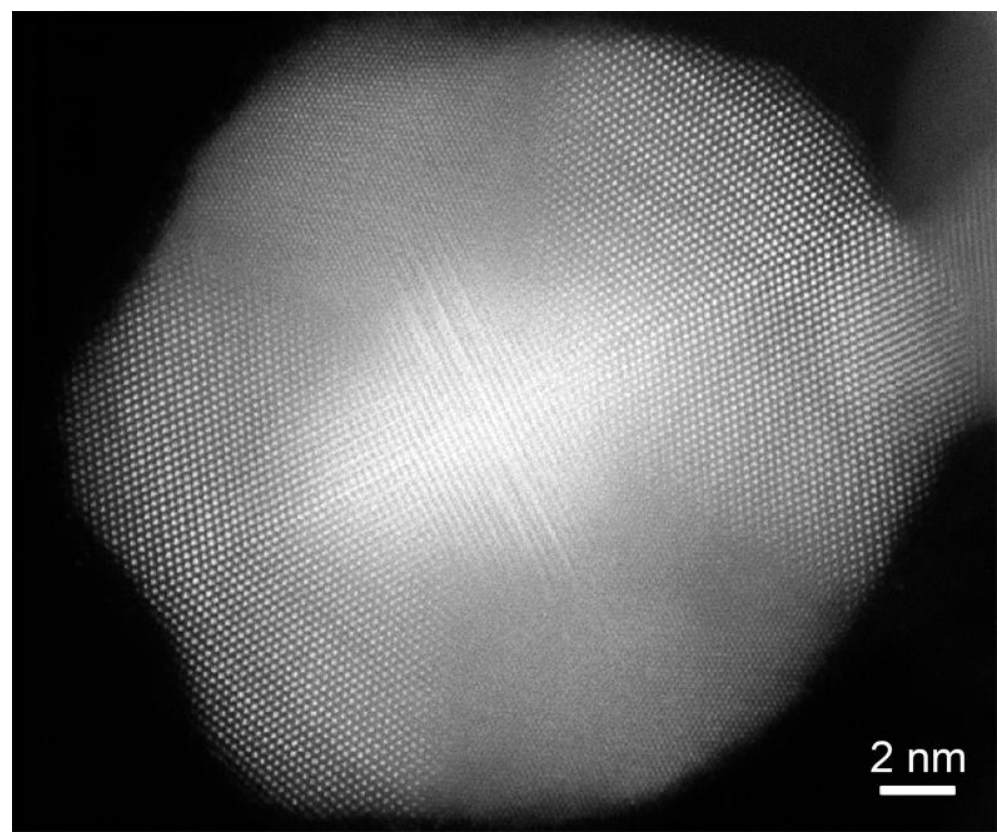

Figure S17. HAADF-STEM image of Pd@PdFe core-shell icosahedra/C after 20000-cycle ADTs. 


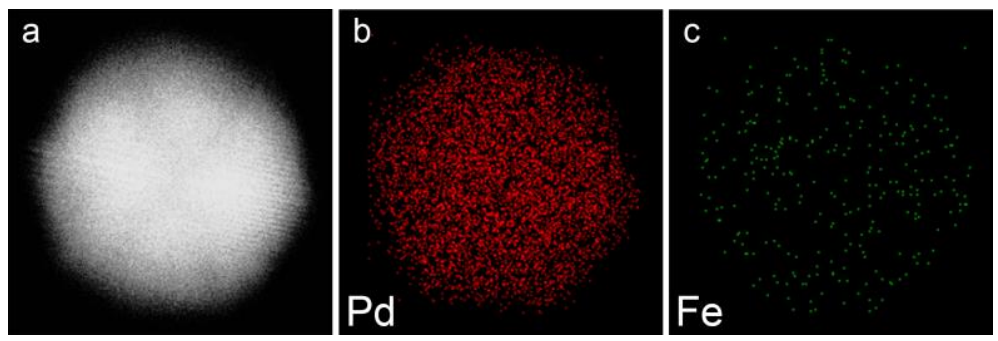

Figure S18. EDX elemental mapping of Pd@PdFe core-shell icosahedra/C after ADTs. 


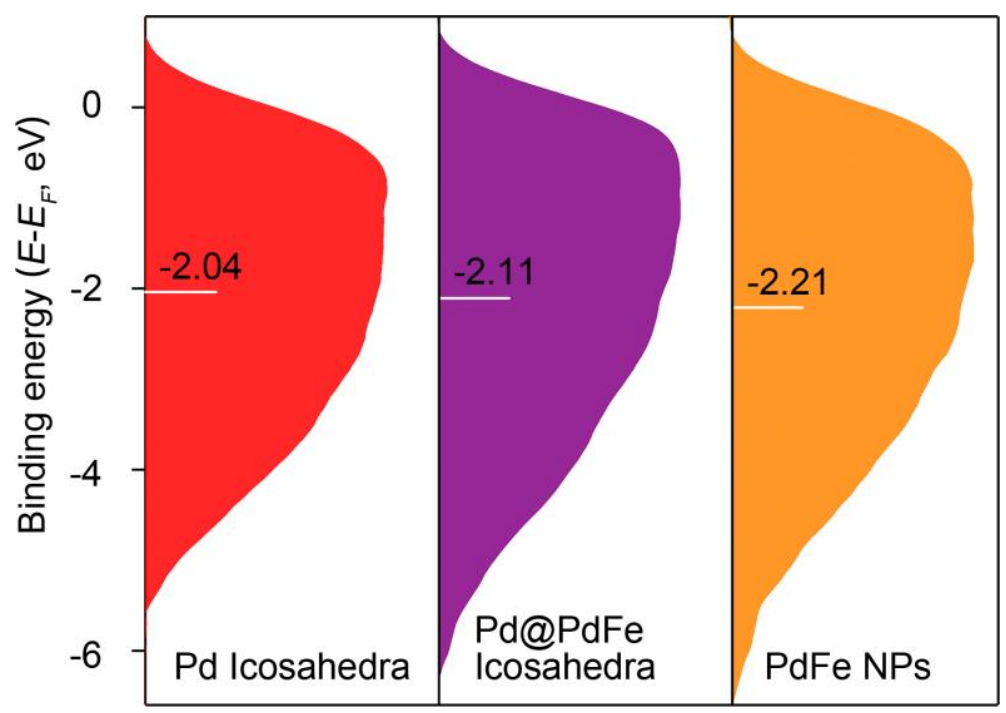

Figure S19. Surface valence bands of Pd-based catalysts. 


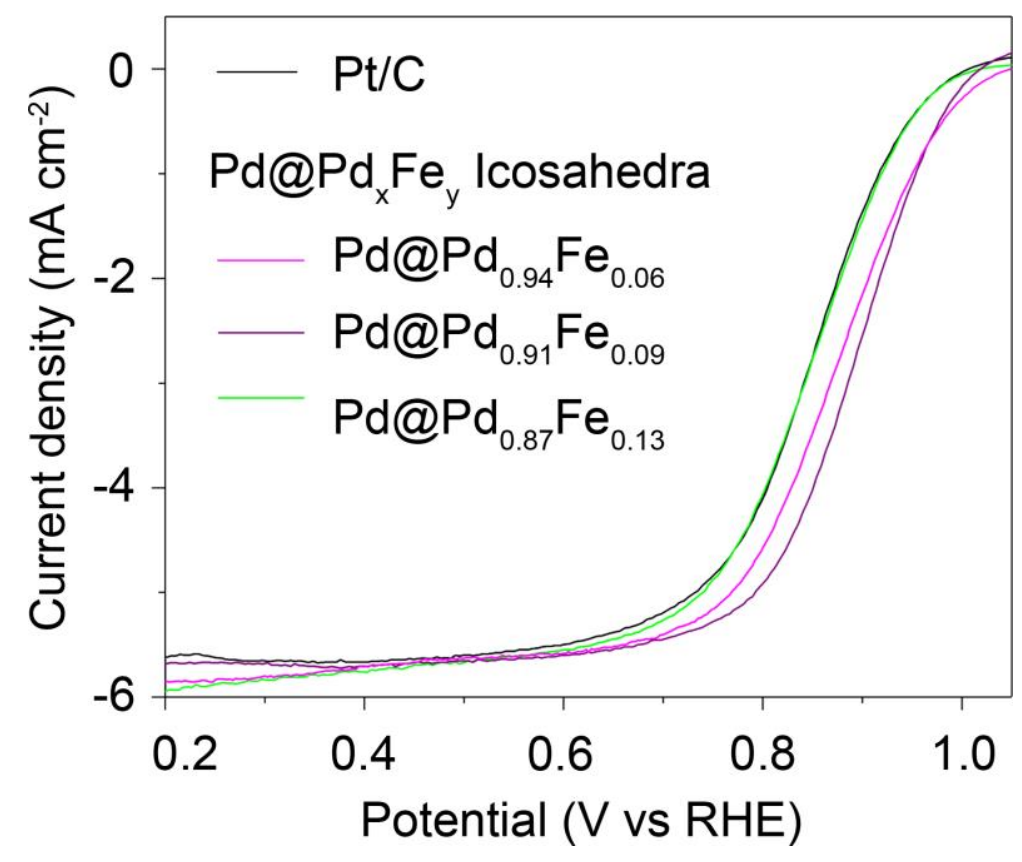

Figure S20. ORR polarization curves of various Fe atomic ratio in the surface shell of $\mathrm{Pd} @ \mathrm{Pd}_{\mathrm{x}} \mathrm{Fe}_{\mathrm{y}}$ core-shell icosahedra/C catalysts. 


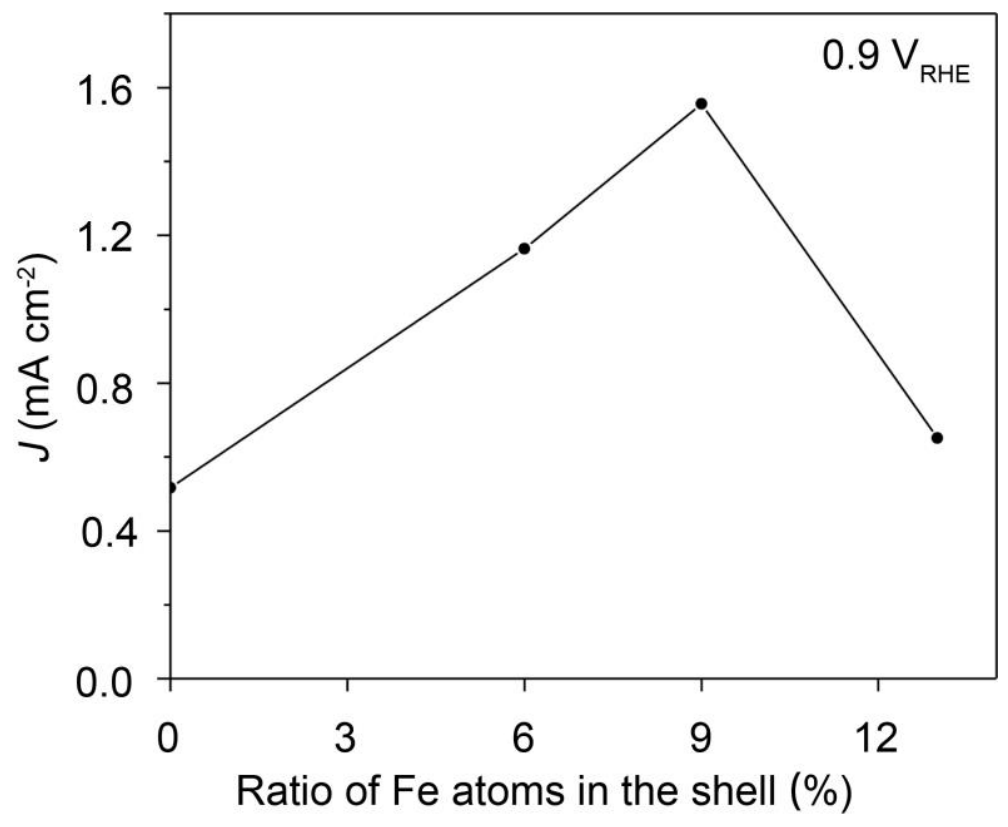

Figure S21. Specific Activities of $\mathrm{Pd} @ \mathrm{Pd}_{\mathrm{x}} \mathrm{Fe}_{\mathrm{y}}$ core-shell icosahedra/C catalysts with different atomic ratios of $\mathrm{Fe}$ in the surface. 


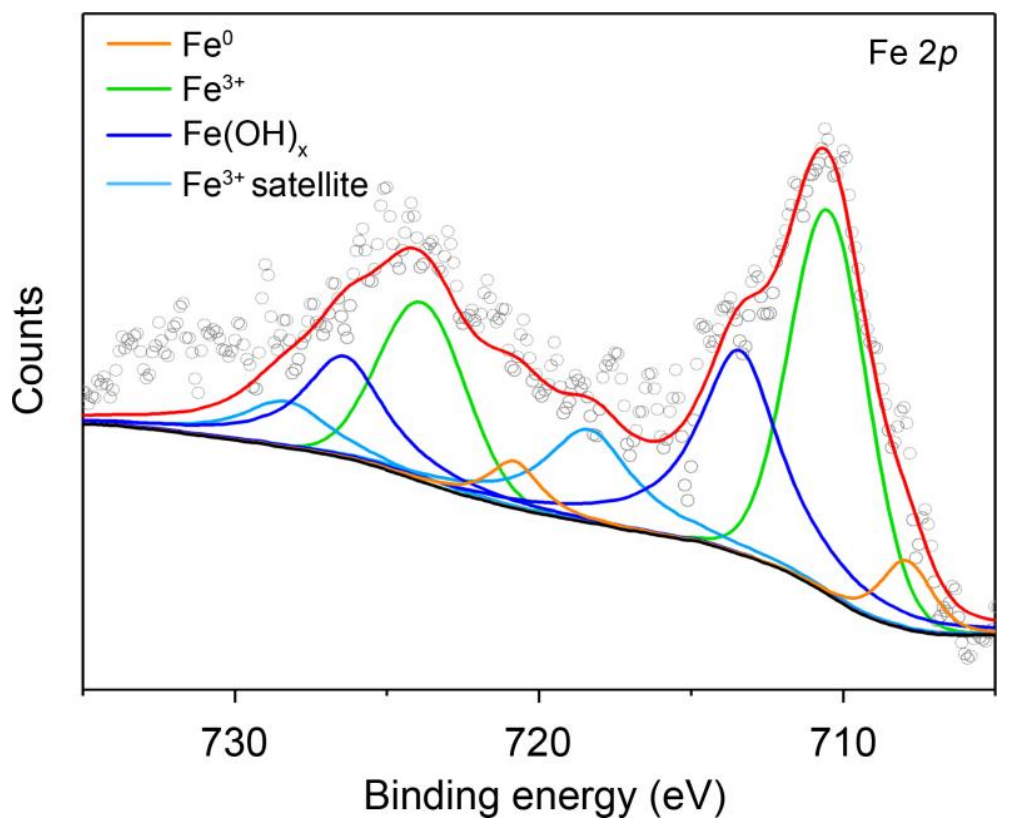

Figure S22. Fe XPS spectrum of synthesized PdFe nanoparticles. 


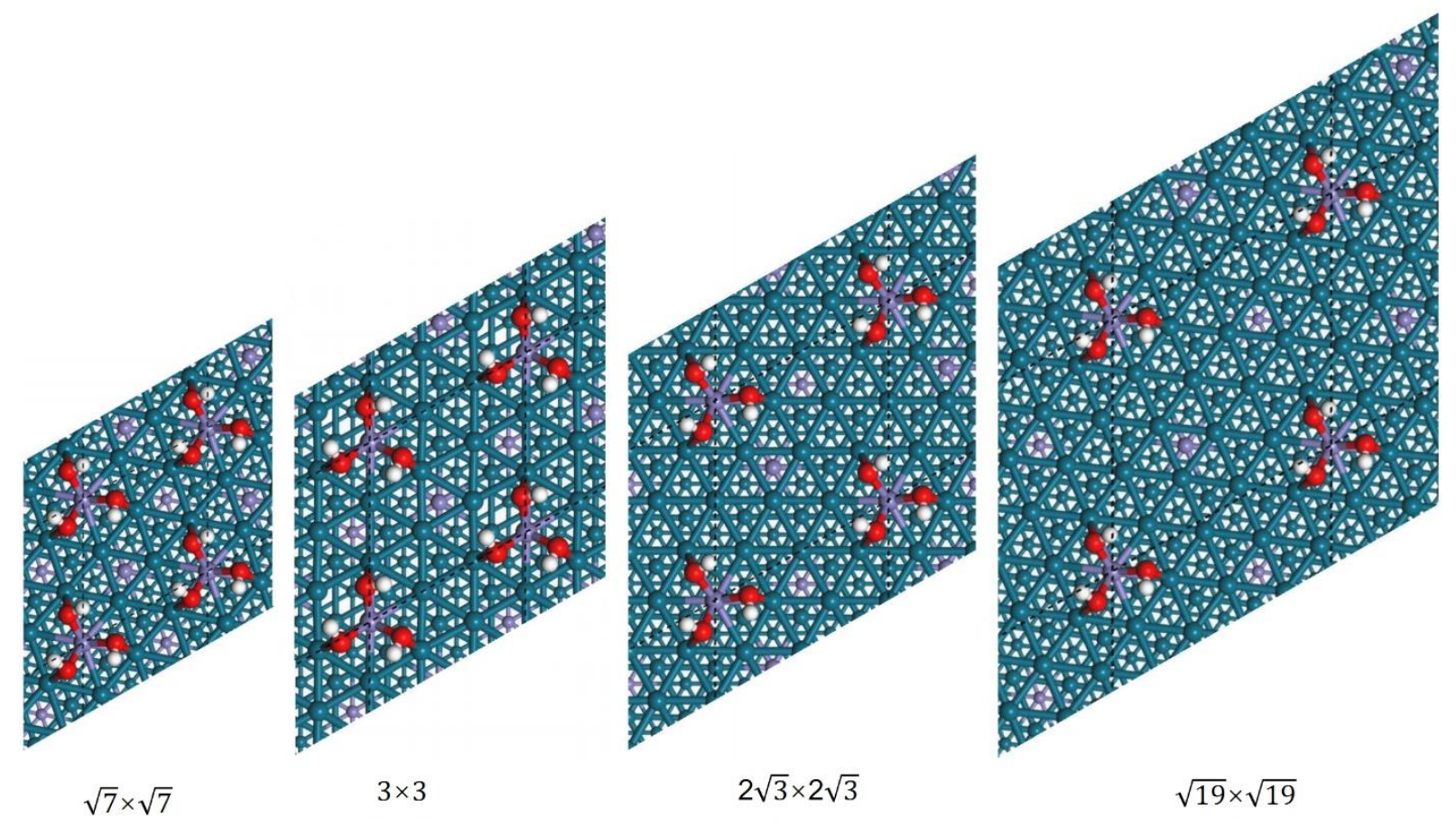

Figure S23. The theoretical model structures for Pd@PdFe core-shell icosahedra with four different Fe concentrations. $\mathrm{Pd}, \mathrm{Fe}, \mathrm{O}, \mathrm{H}$ atoms are represented by dark cyan balls, light magenta balls, red balls and white balls, respectively. Each Fe atom in the outmost Pd layer is saturated by three $\mathrm{OH}$ groups. 


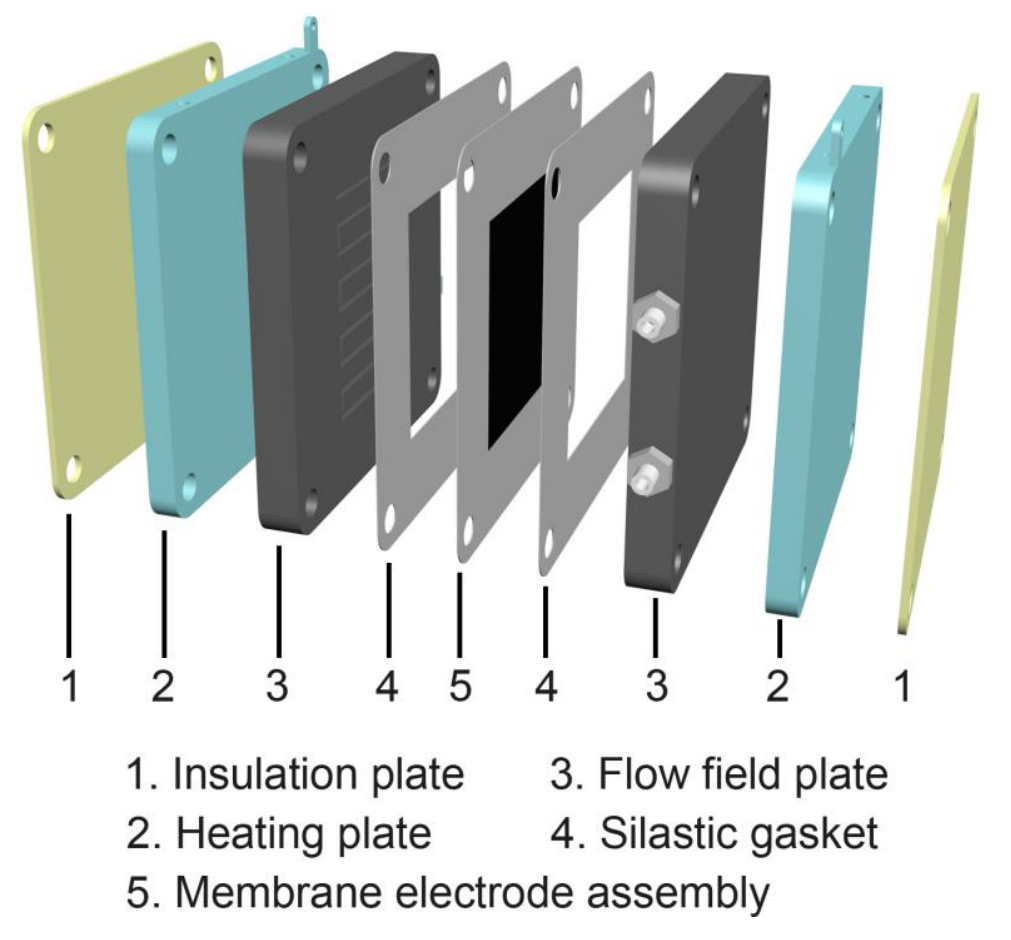

Figure S24. The structure of fuel cell. 


\section{Derivation of Equations for calculating $\mathrm{Fe}$ atomic ratio in the shell}

Derivation of equations to calculate the Fe atomic ratio in the shell as a function of particle side length (a) and thickness of shell (x). ICP-AES acquired Fe atomic ratio (y) in the whole particles. Take Pd@PdFe core-shell icosahedra as an example:

Since Pd seed is icosahedron and the surface triangle with a side length (a), and that of Pd@PdFe core-shell icosahedron is denoted as b, respectively. The size of icosahedral particles was measured between two opposite parallel facets, it was $\frac{\sqrt{3}(3+\sqrt{5})}{6} a$. Surface Fe has a uniform distribution.

Thickness of shell: $\mathrm{x}=\frac{\sqrt{3}(3+\sqrt{5})}{6}(b-a)$;

Volume of core: $\mathrm{V}_{\text {core }}=V_{P d \text { seed }}=\frac{(15+5 \sqrt{5})}{12} a^{3}$;

Volume of shell: $\mathrm{V}_{\text {shell }}=V_{P d @ P d F e}-V_{P d \text { seed }}=\frac{(15+5 \sqrt{5})}{12}\left(b^{3}-a^{3}\right)$;

$\mathrm{Pd} \& \mathrm{Fe}$ atomic ratio in the shell: $\mathrm{R}_{\mathrm{Pd} \& \mathrm{Fe}}=\frac{V_{P d @ P d F e}-V_{P d \text { seed }}}{V_{P d @ P d F e}}=\frac{b^{3}-a^{3}}{b^{3}}=1-\left(\frac{a}{b}\right)^{3}$;

So, Fe atomic ratio in the shell: $\mathrm{R}_{\mathrm{Fe}}=\frac{y}{1-\left(\frac{a}{b}\right)^{3}}$. 
Table S2. Summary of activities on Pd-based catalysts for oxygen reduction reaction (ORR).

\begin{tabular}{|c|c|c|c|c|}
\hline Catalysts & Test Condition & $\begin{array}{l}\text { Specific Activity } \\
\left(\mathbf{m A} / \mathbf{c m}^{2}\right)\end{array}$ & $\begin{array}{l}\text { Mass Activity } \\
(\mathrm{A} / \mathrm{mg})\end{array}$ & Reference \\
\hline $\begin{array}{l}\mathrm{Rh}_{20} \mathrm{Pd}_{80} / \mathrm{C} \\
\text { Nanodendrites }\end{array}$ & $\begin{array}{c}0.1 \mathrm{M} \mathrm{KOH} \\
\text { Scan rate: } 10 \mathrm{mV} \cdot \mathrm{s}^{-1}\end{array}$ & - & $0.48\left(0.8 \mathrm{~V}_{\mathrm{RHE}}\right)$ & S8 \\
\hline $\begin{array}{l}\text { Pd tetrahedron } \\
/ \mathrm{W}_{18} \mathrm{O}_{49}\end{array}$ & $\begin{array}{c}0.1 \mathrm{M} \mathrm{KOH} \\
\text { Scan rate: } 10 \mathrm{mV} \cdot \mathrm{s}^{-1}\end{array}$ & $0.45\left(0.9 \mathrm{~V}_{\mathrm{RHE}}\right)$ & 0.216 (0.9 VRHE $)$ & S9 \\
\hline $\begin{array}{l}\text { Nanoporous } \\
\text { PdNi }\end{array}$ & $\begin{array}{c}0.1 \mathrm{M} \mathrm{KOH} \\
\text { Scan rate: } 10 \mathrm{mV} \cdot \mathrm{s}^{-1}\end{array}$ & - & $0.4\left(0.85 \mathrm{~V}_{\mathrm{RHE}}\right)$ & S10 \\
\hline $\begin{array}{l}\text { Cu3Pd/Graphene } \\
\text { Nanoparticle }\end{array}$ & $\begin{array}{c}0.1 \mathrm{M} \mathrm{KOH} \\
\text { Scan rate: } 50 \mathrm{mV} \cdot \mathrm{s}^{-1}\end{array}$ & - & $0.045\left(0.75 \mathrm{~V}_{\mathrm{RHE}}\right)$ & S11 \\
\hline $\begin{array}{l}\text { Ordered } \\
\mathrm{PdCuCo} / \mathrm{C} \\
\text { Nanoparticle }\end{array}$ & $\begin{array}{c}0.1 \mathrm{M} \mathrm{NaOH} \\
\text { Scan rate: } 10 \mathrm{mV} \cdot \mathrm{s}^{-1}\end{array}$ & - & $\begin{array}{c}0.13\left(0.9 \mathrm{~V}_{\mathrm{RHE}}\right) \\
0.37\left(0.875 \mathrm{~V}_{\mathrm{RHE}}\right)\end{array}$ & S12 \\
\hline $\begin{array}{l}\mathrm{Pd}_{59} \mathrm{Cu}_{30} \mathrm{Co} 11 \\
\text { Nanodendrite }\end{array}$ & $\begin{array}{c}0.1 \mathrm{M} \mathrm{KOH} \\
\text { Scan rate: } 10 \mathrm{mV} \cdot \mathrm{s}^{-1}\end{array}$ & $0.90\left(0.9 \mathrm{~V}_{\mathrm{RHE}}\right)$ & $0.38\left(0.9 \mathrm{~V}_{\mathrm{RHE}}\right)$ & S13 \\
\hline $\begin{array}{l}\mathrm{Pd}_{6} \mathrm{Ni} \\
\text { icosahedra }\end{array}$ & $\begin{array}{c}0.1 \mathrm{M} \mathrm{KOH} \\
\text { Scan rate: } 10 \mathrm{mV} \cdot \mathrm{s}^{-1}\end{array}$ & $0.66\left(0.9 \mathrm{~V}_{\mathrm{RHE}}\right)$ & $0.22\left(0.9 \mathrm{~V}_{\mathrm{RHE}}\right)$ & S14 \\
\hline $\begin{array}{l}\mathrm{Pd}_{31} \mathrm{Bi}_{12} \\
\text { thin film }\end{array}$ & $\begin{array}{c}0.1 \mathrm{M} \mathrm{KOH} \\
\text { Scan rate: } 20 \mathrm{mV} \cdot \mathrm{s}^{-1}\end{array}$ & $9.20\left(0.9 \mathrm{~V}_{\mathrm{RHE}}\right)$ & $\sim 0.11\left(0.9 \mathrm{~V}_{\mathrm{RHE}}\right)$ & S15 \\
\hline $\begin{array}{l}\mathrm{Rh}_{8} \mathrm{Pd}_{92} \\
\text { Octahedron }\end{array}$ & $\begin{array}{c}0.1 \mathrm{M} \mathrm{HClO}_{4} \\
\text { Scan rate: } 10 \mathrm{mV} \cdot \mathrm{s}^{-1}\end{array}$ & - & $0.26\left(0.9 \mathrm{~V}_{\mathrm{RHE}}\right)$ & S16 \\
\hline $\begin{array}{l}\mathrm{PdCuCo} \\
\text { anisotropic } \\
\text { structure }\end{array}$ & $\begin{array}{c}0.1 \mathrm{M} \mathrm{HClO}_{4} \\
\text { Scan rate: } 10 \mathrm{mV} \cdot \mathrm{s}^{-1}\end{array}$ & $0.252\left(0.9 \mathrm{~V}_{\mathrm{RHE}}\right)$ & $0.178\left(0.9 \mathrm{~V}_{\mathrm{RHE}}\right)$ & S17 \\
\hline $\begin{array}{l}\mathrm{Pd}_{0.90} \mathrm{Ni}_{0.10} \\
\text { Nanowire }\end{array}$ & $\begin{array}{c}0.1 \mathrm{M} \mathrm{HClO}_{4} \\
\text { Scan rate: } 10 \mathrm{mV} \cdot \mathrm{s}^{-1}\end{array}$ & $1.96\left(0.8 \mathrm{~V}_{\mathrm{RHE}}\right)$ & - & S18 \\
\hline $\mathrm{Pd}-\mathrm{Co} / \mathrm{gCN}$ & $\begin{array}{c}1 \mathrm{M} \mathrm{H}_{2} \mathrm{SO}_{4} \\
\text { Scan rate: } 10 \mathrm{mV} \cdot \mathrm{s}^{-1}\end{array}$ & $5.8\left(0.65 \mathrm{~V}_{\mathrm{RHE}}\right)$ & - & S19 \\
\hline $\begin{array}{l}\text { Acid etched } \\
\text { PdFe-nanoleaves }\end{array}$ & $\begin{array}{c}0.1 \mathrm{M} \mathrm{NaOH} \\
\text { Scan rate: } 10 \mathrm{mV} \cdot \mathrm{s}^{-1}\end{array}$ & $0.312\left(0.93 \mathrm{~V}_{\mathrm{RHE}}\right)$ & $0.159\left(0.93 \mathrm{~V}_{\mathrm{RHE}}\right)$ & S20 \\
\hline ordered $\mathrm{Pd}_{3} \mathrm{Fe} / \mathrm{C}$ & $\begin{array}{c}0.1 \mathrm{M} \mathrm{KOH} \\
\text { Scan rate: } 10 \mathrm{mV} \cdot \mathrm{s}^{-1}\end{array}$ & - & 0.097 (0.9 $\left.\mathrm{V}_{\mathrm{RHE}}\right)$ & S21 \\
\hline ordered $\mathrm{Pd}_{3} \mathrm{~Pb} / \mathrm{C}$ & $\begin{array}{c}0.1 \mathrm{M} \mathrm{KOH} \\
\text { Scan rate: } 10 \mathrm{mV} \cdot \mathrm{s}^{-1}\end{array}$ & - & $0.169\left(0.9 \mathrm{~V}_{\mathrm{RHE}}\right)$ & S22 \\
\hline $\begin{array}{l}\text { Pd@PdFe } \\
\text { core-shell } \\
\text { icosahedra }\end{array}$ & $\begin{array}{c}0.1 \mathrm{M} \mathrm{KOH} \\
\text { Scan rate: } 10 \mathrm{mV} \cdot \mathrm{s}^{-1}\end{array}$ & $\begin{array}{c}1.56\left(0.9 \mathrm{~V}_{\mathrm{RHE}}\right) \\
4.71\left(0.85 \mathrm{~V}_{\mathrm{RHE}}\right)\end{array}$ & $\begin{array}{c}0.31\left(0.9 \mathrm{~V}_{\mathrm{RHE}}\right) \\
0.91\left(0.85 \mathrm{~V}_{\mathrm{RHE}}\right)\end{array}$ & This work \\
\hline
\end{tabular}




\section{REFERENCES}

(1) Niu, Z.; Peng, Q.; Gong, M.; Rong, H.; Li, Y. Angew. Chem. Int. Ed. 2011, 50, 6315-6319.

(2) Zhou, X.; Johnson, R.; Wadley, H. Phys. Rev. B 2004, 69, 144113.

(3) Zhong, H.; Wang, J.; Zhang, Y.; Xu, W.; Xing, W.; Xu, D.; Zhang, Y.; Zhang, X. Angew. Chem. Int. Ed. 2014, 53, 14235-14239.

(4) Perdew, J. P.; Burke, K.; Ernzerhof, M. Phys. Rev. Lett. 1996, 77, 3865.

(5) Grimme, S.; Antony, J.; Ehrlich, S.; Krieg, H. J. Chem. Phys. 2010, 132, 154104.

(6) Grimme, S.; Ehrlich, S.; Goerigk, L. J. Comput. Chem. 2011, 32, 1456-1465.

(7) Blöchl, P. E. Phys. Rev. B 1994, 50, 17953.

(8) Qi, Y.; Wu, J.; Zhang, H.; Jiang, Y.; Jin, C.; Fu, M.; Yang, H.; Yang, D. Nanoscale 2014, 6, 7012-7018.

(9) Lu, Y.; Jiang, Y.; Gao, X.; Wang, X.; Chen, W. J. Am. Chem. Soc. 2014, 136, 11687-11697.

(10)Chen, L.; Guo, H.; Fujita, T.; Hirata, A.; Zhang, W.; Inoue, A.; Chen, M. Adv. Funct. Mater. 2011, 21, 4364-4370.

(11)Zheng, Y.; Zhao, S.; Liu, S.; Yin, H.; Chen, Y.-Y.; Bao, J.; Han, M.; Dai, Z. ACS Appl. Mater. Interfaces 2015, 7, 5347-5357.

(12)Jiang, K.; Wang, P.; Guo, S.; Zhang, X.; Shen, X.; Lu, G.; Su, D.; Huang, X. Angew. Chem. Int. Ed. 2016, 55, 9030-9035.

(13)Li, C.; Yuan, Q.; Ni, B.; He, T.; Zhang, S.; Long, Y.; Gu, L.; Wang, X. Nat. Commun. 2018, 9, 3702 .

(14)Feng, Y.; Shao, Q.; Ji, Y.; Cui, X.; Li, Y.; Zhu, X.; Huang, X. Sci. Adv. 2018, 4, eaap8817.

(15)Wang, Y.; Sun, D.; Chowdhury, T.; Wagner, J.; Kempa, T. J.; Hall, A. S. J. Am. Chem. Soc. 2019, 141, 2342-2347.

(16) Yan, Y.; Zhan, F.; Du, J.; Jiang, Y.; Jin, C.; Fu, M.; Zhang, H.; Yang, D. Nanoscale 2015, 7, 301-307.

(17)Zuo, Y.; Rao, D.; Li, S.; Li, T.; Zhu, G.; Chen, S.; Song, L.; Chai, Y.; Han, H. Adv. Mater. 2018, 30, 1704171.

(18)Liu, H.; Koenigsmann, C.; Adzic, R. R.; Wong, S. S. ACS Catal. 2014, 4, 2544-2555.

(19) Ghosh, A.; Chandran, P.; Ramaprabhu, S. Appl. Energy 2017, 208, 37-48.

(20)Zhang, Z.; More, K.; Sun, K.; Wu, Z.; Li, W. Chem. Mater. 2011, 23, 1570-1577.

(21)Cui, Z.; Li, L.; Manthiram, M.; Goodenough, J. J. Am. Chem. Soc. 2015, 137, 7278-7281. 
(22)Cui, Z.; Chen, H.; Zhao, M.; DiSalvo, F. Nano Lett. 2016, 16, 2560-2566. 